\title{
Cultural Factors, Economic Affiliations And The Adoption Of International Financial Reporting Standards
}

\author{
Presha E. Neidermeyer. Ph.D., CPA, West Virginia University, USA \\ Jack Dorminey, Ph.D., West Virginia University, USA \\ Alan J. Wilson, West Virginia University, USA
}

\begin{abstract}
We examine cultural characteristics in the context of economic affiliation and the timing of IFRS adoption. Prior work identifies cultural characteristics as key factors in the development of accounting systems world-wide. Our analysis extends this literature by showing that these same factors lead to economic clusters and to the propensity for adopting a universally accepted set of accounting rules. We contribute to the literature by demonstrating that, at least in one case, cultural factors are able to predict economic affiliations. Second, we provide evidence that certain cultural characteristic are affiliated with the delay in adoption of IFRS. Our results are valuable to local as well as international accounting standard setters as they look to negotiate common ground for convergence. Our examination of the cultural aspects distinctive in adoption patterns may provide insight into what specific aspects of the IFRS must be modified to expand and accelerate convergence.
\end{abstract}

Keywords: International Financial Reporting Standards (IFRS); Hofstede; Professional Values; Globalization

\section{INTRODUCTION}

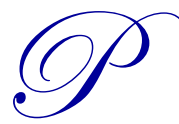

rogress toward a universal conversion to International Financial Reporting Standards (IFRS) has been relatively quick in terms of the evolution of business practices. One of the more significant steps toward a universally accepted set of accounting standards occurred when the European Union required all constituent states to implement IFRS by 2005. Indeed, in looking at a world map, well over 100 countries have already adopted IFRS and all continents are significantly impacted. ${ }^{1}$.

Research continues to consider the cost-benefit relationship of IFRS adoption. Prior studies on the benefits of IFRS adoption address the commonly cited benefits of increased transparency, improved comparability, and greater foreign investment. In the year following adoption, firms experience decreases in costs of capital and increases in market liquidity between 3-6\% (Daske, 2008). Late adopters (those adopting after 2006) benefit from the learning curve created by the earlier adopters. Active promotion and training workshops address much of the uncertainty and mitigate the disadvantages experienced by first movers. Beyond these advantages, countries adopt out of the fear that non-IFRS compliance will not encourage, and may decrease, foreign investment (Leng, 2008).

Other research addresses the impediments to IFRS adoption and presents compelling arguments against the potential benefits derived from the proposed cost reductions. In countries with high levels of anti-fraud protection, the principles-based nature of IFRS adds concerns to the level of investor protection under the IFRS system. In 2008, forty-four percent of all filed securities-fraud complaints cited a GAAP violation. The extensive rules-based nature of U.S. GAAP provides investors (plaintiffs) a greater degree of leverage in proving a material misstatement at trial. The principles of IFRS do not offer the same advantage when proving misstatements in a court proceeding (Phillips, 2010).

\footnotetext{
${ }^{1}$ For a full listing of IFRS adoption see: http://www.iasb.org/Use+around+the+world/Use+around+the+world.htm 
Prior research also asserts a link between the political prestige of a country and its willingness to adopt IFRS, with more powerful ones resisting IFRS to a greater extent than those with less political influence. Countries that perceive IFRS adoption as ceding standard-setting power to the EU demonstrate a higher degree of aversion to IFRS. Network trends may also exert influence on a country's desire to participate in IFRS. Current data indicate a correlation between a country's adoption of IFRS and its adoption by surrounding nations or by other countries with significant political standing (Ramanna, 2009).

With the movement in international markets toward convergence to IFRS as either the default system of financial reporting or an alternative to the national system of reporting, the current research posits that cultural commonalities among adopting countries may impact the timing of such adoption. The influence of culture on the development of accounting systems and financial reporting has been widely studied. Hofstede's work on mapping culture into four dimensions forms the basis of much of this inquiry. Hofstede defines culture as the systematic programming of the mind and he posits (1980) that there are four cultural dimensions: individualism (versus collectivism), power distance, uncertainty avoidance, and masculinity (versus femininity). These dimensions impact the manner in which people process information.

Individualism (IDV) is a measure of how much a society encourages individual accomplishments and loose relationships versus collective accomplishments and close relationships. A society that ranks highly in individualism usually places importance on individual achievements, whereas one that ranks low in individualism focuses more on the importance of collective achievement. (Hofstede, 1998.)

Power Distance (PD) measures the degree of equality in a society. One that ranks high in power distance places importance on status and is distinguished by differences between people in terms of wealth and power. Where power distance is low, fewer of these inequalities are noted and opportunities are available for all. (Hofstede, 1998.)

Uncertainty Avoidance (UA) refers to a society's ability to cope with the unknown. High uncertainty avoidance means that the society feels more of a need to know future outcomes than one with low uncertainty avoidance. Societies with high uncertainty avoidance generally have more laws (so as to be able to restrict the range of outcomes) whereas lower levels of uncertainty avoidance allow for a more open society. (Hofstede, 1998.)

Masculinity (MAS) is a measure of the traditional masculine traits of a society: control, power, and achievement. In a highly masculine society there would be significant differentiation between genders, while in more feminine societies there would exist a greater focus on people and their relationships to one another. (Hofstede, 1998.)

\section{DETERMINANTS OF ACCOUNTING VALUES}

Gray (1988) demonstrated how cultural factors affect the development of accounting values and how an agreed upon set of accounting values gives rise to the development of accounting systems (internationally). Gray posited four accounting values arising from Hofstede's cultural dimensions. He extended the model of corporate reporting to include:

- $\quad$ External influences - such as trade and investment;

- $\quad$ Ecological influences - such as geographic and historical;

- Cultural dimensions - power distance, uncertainty avoidance, masculinity (femininity), individualism (collectivism);

- $\quad$ Accounting Values - such as professionalism, uniformity, secrecy, and conservatism;

- Institutional Consequences - such as legal systems and education; and,

- $\quad$ Accounting Systems - such as authority, enforcement, measurement, and disclosure.

Nobes (1998) reduced the variables in Gray's (1988) system to two distinct variables, which he called culture and the nature of the accounting systems. He asserted that these differences are the result of the distinct outcomes desired by each of the national systems. 


\section{CULTURAL INFLUENCES OF ECONOMIC AFFILIATION}

Historically, distinct desired outcomes have led to the development of different reporting mechanisms within financial accounting standards, but more recent changes in the world business environment have made such a multiplicity of financial reporting rules undesirable. First and foremost among these is the inability to compare international financial statements without considerable effort on the part of the stakeholder. While international investment opportunities traditionally have been more limited, technological innovations have led to an increase in the number of stakeholders desiring to acquire international equity, thus increasing the number of individuals and businesses impacted by international accounting diversity. Standard-setting bodies and national regulatory agencies have reacted to this problem largely by adopting IFRS as a compliment to, or in replacement of, their older national standards. This adoption has allowed international investors to make comparisons between companies on differentiated securities exchanges much more easily, as this can be done without significant (or frequently any) conversions of the financial reports.

Prior literature shows that countries with similar values on the Hofstede measures tend to have other social similarities including business activities (Lin et al., 2008). Further, research shows that countries with similar cultural foundations are more likely to trade with one-another. Membership in the European Union offers benefits such as trade and the ability of citizens to move between member states for employment. Membership also has its obligations, however. One of these is the requirement for consolidated financial reporting, where publicly traded companies must use IFRS as the reporting medium. Thus, as a precursor to a larger discussion of adoption of IFRS in the world economies, the Union may have experienced a centric cultural migration in order to facilitate the formation of such a cohesive economic policy. Because economic affiliations tend to form along cultural similarities, we expect that the numeric values in Hofstede's cultural dimensions are associated with European Union membership.

Hypothesis 1: Cultural factors are associated with European Union membership.

A comprehensively comparable system of financial reporting is undoubtedly valuable; however, varying levels of resistance to IFRS adoption remain. In light of the obvious benefits of an international set of standards, we posit that resistance to or delay in IFRS adoption is related to relatively stable cultural, societal, and economic factors. Higher levels of IDV, MAS, and UA are expected to be associated with later adoption of IFRS. Higher values of PD are expected to be associated with earlier adoption of IFRS.

In addition to the Hofstede measures, we anticipate that other country-specific factors influence the timing of IFRS adoption. Prior literature shows that a country's native accounting system is heavily influenced by that country's economic and legal systems. Accordingly, we expect that the economic and legal systems of a country will influence the timing of IFRS adoption.

Hypothesis 2: Cultural characteristics, size of the economy, legal system, economic affiliation, and economic market orientation (micro vs. macro) affect the timing of IFRS adoption.

\section{Sample}

Our analysis examines the relationship between the cultural characteristics of $37{ }^{2}$ countries and the timing of IFRS adoption. According to the IASB, as of the end of 2009, over 100 sovereigns have adopted IFRS as their primary authoritative financial reporting regime (IASB 2010). Hofstede measures are available for 23 of these countries. An additional 14 countries which have not yet adopted IFRS, but do have Hofstede measures available, are also included in our study. The dataset is presented as Table 1.

\footnotetext{
${ }^{2}$ Our total sample consists of 39 countries. We utilize all 39 countries in our examination of European Union membership. However, because the information concerning the legal systems of Iran and Turkey does not exist in the MICRO/MACRO framework, those two countries are excluded from our analysis of IFRS adoption. Therefore, only 37 countries are included in the analysis of characteristics relating to the timing of IFRS adoption.
}

(c) 2012 The Clute Institute http://www.cluteinstitute.com/ 
Table 1: Data Set and Variable Names

\begin{tabular}{|c|c|c|c|c|c|c|c|c|c|c|}
\hline COUNTRY & ADOPTION $^{3}$ & DELAY & MAS & IDV & UA & PD & LEGAL & MACRO & UNION & GNP \\
\hline Argentina & 2011 & 9 & 56 & 46 & 86 & 49 & 1 & 1 & 0 & 284.20 \\
\hline Australia & 2005 & 3 & 61 & 90 & 51 & 36 & 1 & 0 & 0 & 389.96 \\
\hline Austria & 2005 & 3 & 79 & 55 & 70 & 11 & 1 & 1 & 0 & 191.76 \\
\hline Belgium & 2005 & 3 & 54 & 75 & 94 & 65 & 1 & 1 & 1 & 232.63 \\
\hline Brazil & 2010 & 8 & 49 & 38 & 76 & 69 & 1 & 1 & 0 & 644.28 \\
\hline Canada & 2011 & 9 & 52 & 80 & 48 & 39 & 1 & 0 & 0 & 725.16 \\
\hline Chile & 2010 & 8 & 28 & 23 & 86 & 63 & 1 & 1 & 0 & 75.20 \\
\hline Colombia & 2016 & 14 & 64 & 13 & 80 & 67 & 1 & 1 & 0 & 94.08 \\
\hline Denmark & 2005 & 3 & 16 & 74 & 23 & 18 & 1 & 1 & 1 & 160.53 \\
\hline Finland & 2005 & 3 & 26 & 63 & 59 & 33 & 1 & 1 & 1 & 122.15 \\
\hline France & 2005 & 3 & 43 & 71 & 86 & 68 & 1 & 1 & 1 & $1,333.20$ \\
\hline Germany & 2005 & 3 & 66 & 67 & 65 & 35 & 1 & 1 & 1 & $1,905.80$ \\
\hline Great Britain & 2005 & 3 & 66 & 89 & 35 & 35 & 1 & 0 & 1 & $1,480.53$ \\
\hline Greece & 2005 & 3 & 57 & 35 & 112 & 60 & 1 & 1 & 1 & 127.60 \\
\hline Hong Kong & 2005 & 3 & 57 & 25 & 29 & 68 & 1 & 0 & 0 & 169.12 \\
\hline India & 2016 & 14 & 56 & 48 & 40 & 77 & 1 & 0 & 0 & 461.91 \\
\hline Iran & 2016 & 14 & 43 & 41 & 59 & 58 & 0 & 1 & . & 96.44 \\
\hline Ireland & 2005 & 3 & 68 & 70 & 35 & 28 & 1 & 0 & 1 & 96.88 \\
\hline Israel & 2008 & 6 & 47 & 54 & 81 & 13 & 0 & 1 & 0 & 123.69 \\
\hline Italy & 2016 & 14 & 70 & 76 & 75 & 50 & 1 & 1 & 1 & $1,100.56$ \\
\hline Japan & 2015 & 13 & 95 & 46 & 92 & 54 & 1 & 1 & 0 & $4,668.79$ \\
\hline Mexico & 2012 & 10 & 69 & 30 & 82 & 81 & 1 & 1 & 0 & 628.85 \\
\hline Netherlands & 2005 & 3 & 14 & 80 & 53 & 38 & 1 & 0 & 1 & 386.20 \\
\hline New Zealand & 2002 & 0 & 58 & 79 & 49 & 22 & 1 & 0 & 0 & 2.37 \\
\hline Norway & 2005 & 3 & 8 & 69 & 50 & 31 & 0 & 1 & 1 & 168.67 \\
\hline Pakistan & 2009 & 7 & 50 & 14 & 70 & 55 & 1 & 1 & 0 & 74.08 \\
\hline Peru & 2016 & 14 & 42 & 16 & 87 & 64 & 1 & 1 & 0 & 53.32 \\
\hline Philippines & 2005 & 3 & 64 & 32 & 44 & 94 & 0 & 0 & 0 & 75.91 \\
\hline Portugal & 2005 & 3 & 31 & 27 & 104 & 63 & 1 & 1 & 1 & 112.98 \\
\hline Singapore & 2016 & 14 & 48 & 20 & 8 & 74 & 1 & 0 & 0 & 92.72 \\
\hline South Africa & 2003 & 1 & 63 & 65 & 49 & 49 & 0 & 0 & 0 & 132.96 \\
\hline Spain & 2005 & 3 & 42 & 51 & 86 & 57 & 1 & 1 & 1 & 582.38 \\
\hline Sweden & 2005 & 3 & 5 & 71 & 29 & 31 & 1 & 1 & 1 & 246.37 \\
\hline Switzerland & 2016 & 14 & 70 & 68 & 58 & 34 & 1 & 1 & 0 & 250.20 \\
\hline Taiwan & 2016 & 14 & 45 & 17 & 69 & 58 & 1 & 0 & 0 & 321.37 \\
\hline Thailand & 2016 & 14 & 34 & 20 & 64 & 64 & 1 & 1 & 0 & 122.73 \\
\hline Turkey & 2008 & 6 & 45 & 37 & 85 & 66 & 1 & 1 & . & 266.44 \\
\hline USA & 2014 & 12 & 62 & 91 & 46 & 40 & 1 & 0 & 0 & $9,816.98$ \\
\hline Venezuela & 2008 & 6 & 73 & 12 & 76 & 81 & 0 & 1 & 0 & 117.15 \\
\hline
\end{tabular}

Correlations for all variables in the study are provided in Table 2.

Table 2: Univariate Correlations

\begin{tabular}{|c|c|c|c|c|c|c|c|}
\hline & IDV & MAS & PD & UA & MACRO & LEGAL & $\mathbf{E U}$ \\
\hline IDV & 1.000 & & & & & & \\
\hline MAS & $(0.038)$ & 1.000 & & & & & \\
\hline PD & $(0.660)^{* * *}$ & 0.150 & 1.000 & & & & \\
\hline UA & $(0.329)^{* *}$ & 0.163 & 0.260 & 1.000 & & & \\
\hline MACRO & $(0.268)$ & $(0.145)$ & 0.001 & $0.640^{* * * *}$ & 1.000 & & \\
\hline LEGAL & 0.091 & 0.022 & $(0.067)$ & 0.074 & 0.040 & 1.000 & \\
\hline $\mathrm{EU}$ & $0.454^{* * * *}$ & $(0.395)^{* * *}$ & $(0.283)^{*}$ & 0.027 & 0.224 & 0.171 & 1.000 \\
\hline GNP & $0.326^{* *}$ & $0.287^{*}$ & $(0.088)$ & $(0.026)$ & $(0.148)$ & 0.152 & $(0.063)$ \\
\hline
\end{tabular}

Significance at the $\mathrm{p}<.100, \mathrm{p}<.050$, and $\mathrm{p}<.001$ levels are indicated with '*', '**', and '***', respectively.

3 Adoption reflects the year in which the country either has adopted or plans to adopt IFRS. Of the countries with stated intentions, all plan to adopt not later than 2015. Any country without a stated adoption timeline is assigned 2016. In the context of our model, this means that we assume any country without a stated plan will adopt later than all those with a plan. 
Power distance $(P D)$ and individualism (IDV) exhibit a large and statistically significant correlation. Further, three Hofstede measures, power distance $(P D)$, masculinity $(M A S)$, and individualism (IDV), have statistically significant correlations with membership in the European Union $(E U)$.

\section{METHODS}

\section{Cultural factors related to economic affiliation}

We present the univariate statistics for the Hofstede measures dependent on European Union membership. Table 3 provides univariate descriptive statistics for the Hofstede measures for the entire sample, EU members, and non-members. In order to test our first hypothesis, we employ a logistic regression using the Hofstede variables to predict EU membership. That is, we construct a model that predicts the probability that a country is a member of the European Union using only the four Hofstede measures as shown here in equation (1).

$\ln ($ odds ratio that $\mathrm{EU}=1)=\mathrm{b}_{0}+\mathrm{b}_{1} I D V+\mathrm{b}_{2} P D+\mathrm{b}_{3} U A+\mathrm{b}_{4} M A S$

The estimation results of equation (1) are shown in Table 4.

Table 3: Univariate Analysis of Hofstede Metrics by EU Membership

\begin{tabular}{lcccc}
\hline Full Sample & IDV & MAS & PD & UA \\
\hline Mean & 50.72 & 50.67 & 51.23 & 63.87 \\
Median & 51.00 & 54.00 & 55.00 & 65.00 \\
Standard Deviation & 24.82 & 19.64 & 20.13 & 23.73 \\
Maximum & 12.00 & 5.00 & 11.00 & 8.00 \\
Minimum & 91.00 & 95.00 & 94.00 & 112.00 \\
EUUNION=1 & IDV & MAS & PD & UA \\
\hline Mean & 65.57 & 40.43 & 43.71 & 64.71 \\
Median & 70.50 & 42.50 & 36.50 & 62.00 \\
Standard Deviation & 17.01 & 23.71 & 16.24 & 28.85 \\
Maximum & 27.00 & 5.00 & 18.00 & 23.00 \\
Minimum & 89.00 & 70.00 & 68.00 & 112.00 \\
EUUNION=0 & IDV & MAS & PD & UA \\
\hline Mean & 42.40 & 56.40 & 55.44 & 63.40 \\
Median & 38.00 & 56.00 & 58.00 & 69.00 \\
Standard Deviation & 24.86 & 14.53 & 21.15 & 20.98 \\
Maximum & 12.00 & 28.00 & 11.00 & 8.00 \\
Minimum & 91.00 & 95.00 & 94.00 & 92.00 \\
T-test for differences between European Union membership & & & & Higher \\
Hypothesized direction for EU non-members & Lower & Higher & Higher \\
Difference in mean & $(23.17)$ & 15.97 & 11.73 & $(1.31)$ \\
One-tailed p-value (assume unequal variances) & 0.0019 & 0.0064 & 0.0404 & 0.5645 \\
Hypothesis supported? & Yes & Yes & Yes & No \\
\hline
\end{tabular}


Table 4: Classification Model for European Union Membership

\begin{tabular}{lc}
\hline Panel A: Logistic estimation & \\
\hline & Coefficien \\
\hline IDV & 0.0945 \\
PD & 0.0045 \\
UA & 0.0607 \\
MAS & $(0.0769)$ \\
Constant & $(6.2823)$ \\
& \\
Number of obs $=$ & 39 \\
Log likelihood $=$ & $(14.8152)$ \\
LR chi2(4) $=$ & 21.2900 \\
Prob $>$ chi2 $=$ & 0.0003 \\
Pseudo R2 $=$ & 0.4181
\end{tabular}

$\underline{\text { Panel B: Classification table }}$

Predicted as a non-Member

Predicted as a Member

Total

\begin{tabular}{|c|c|c|}
\multicolumn{3}{c}{ Actual EU Membership } \\
Non-Member & Member & Total \\
\hline 21 & 4 & 25 \\
\hline 4 & 10 & 14 \\
\hline 25 & 14 & 39 \\
\hline
\end{tabular}

Correct classification percent ${ }^{1}$

Current model $\quad 79.5 \%$

Naïve model percent

$64.1 \%$

${ }^{1}$ A classification model is valuable only if it is able to predict group member ship more accurately than is the naive model. Classification in the naive model is achieved by simply classifying all observations in the largest group. So in this case, the naive model is correct in approximately 64 percent (25/39) of the cases. Our model is able to accurately classify the dataset in approximately 80 percent $((21+10) / 39)$ of the cases.

The logistic model explains approximately 42 percent of the variation in European Union membership and is significant at the $p<.001$ level. IDV, MAS, and $U A$ are significant at conventional levels. Power Distance $(P D)$ is not significant in the model. As reported in Panel B of Table 4, our model is able to correctly classify 31 of the 39 countries with regard to EU membership. Under a naive classification model, only 25 out of 39 countries are correctly classified. ${ }^{4}$ The results of our classification model lend support to the notion that cultural factors are associated with economic affiliation.

The coefficients estimated in a logistic regression are odds ratios. An odds ratio is the odds (or chances) of being in one group divided by the odds (or chances) of not being in that group. Therefore, an odds ratio greater than 1.0 indicates that an increase in the value of the variable increases the odds of being in the EU more than it increases the odds of not being in the EU. Accordingly, higher levels in $I D V$ and $U A$ increase the odds ratio for inclusion in the EU. Because the odds ratio for MAS is less than 1.0, decreases in MAS result in higher odds ratios for inclusion in the EU. PD exhibits the hypothesized odds ratio effect (greater than 1.0), however, the estimate is not statistically discernible. All other variables exhibit odds ratio that are significant at conventional levels with hypothesized effect. Therefore, we claim support for our first hypothesis.

\section{Factors related to the timing of IFRS adoption}

Our second hypothesis asserts that the timing of IFRS adoption is influenced by the Hofstede measures as well as other country-specific characteristics illustrated in equation (2) below. The timing of adoption (DELAY) is computed for each country as the number of years elapsing between the initial date of 2002 and the year of IFRS

\footnotetext{
${ }^{4}$ A naive model simply classifies all observations (countries) in the largest group. Therefore, the naive model in this case classifies all 39 countries as EU members. The naive model is correct in approximately 64 percent of the cases.
} 
adoption or intended adoption. ${ }^{5}$ For countries that have not set a specific date for adoption, we assign 2016 as the adoption year. ${ }^{6}$ Countries adopting in later years have higher values of DELAY than countries adopting in early years.

In addition to the Hofstede measures, we include a variable $M A C R O$ which takes on the value of 1 if the country tends toward a centrally managed economy and 0 otherwise. Countries with a centrally managed economy are associated with lower levels of political influence from users of financial statements, and are therefore better able to simply impose IFRS. MACRO is expected to be associated with earlier adoptions.

The status that accounting policy holds within a country is closely related to that country's legal system. Legal systems arising from common law typically treat accounting rules as guidance, whereas legal systems arising from code law typically treat accounting rules as law. We represent the legal system with the variable $L G L$, which takes on the value of 1 if the country employs code law and the value of 0 if it utilizes common law. We have no specific hypothesized direction for this variable.

We include per capita gross national product $(G N P)$ in our model as a proxy for the existing level of productivity of a country. Higher productivity is expected to increase the resistance to IFRS adoption. As a specific example, the U.S. is the largest economy not having adopted IFRS, making a control for economic activity necessary to isolate the effect of the Hofstede measures. Finally, we include a control variable $E U$ to indicate if a country is a member of the European Union. Due to the mandated adoption of IRFS by all member nations in 2005 a control for EU membership is necessary.

Because of the strong correlations among the Hofstede measures, and the fact that the Hofstede measures are able to predict EU membership, we suspect a collinearity problem when testing our second hypothesis. To demonstrate the severity of the problem, we compute the variance inflation factors (VIF) for each independent variable in equation (2). Table 5 reports the individual VIFs and average VIFs for our variables.

$D E L A Y=\mathrm{b}_{0}+\mathrm{b}_{1} I D V+\mathrm{b}_{2} P D+\mathrm{b}_{3} U A+\mathrm{b}_{4} M A S+\mathrm{b}_{5} M A C R O+\mathrm{b}_{6} L E G A L+\mathrm{b}_{7} E U+\mathrm{b}_{8} G N P+\mathrm{e}$

Table 5: Variance Inflation Factors ${ }^{1}$

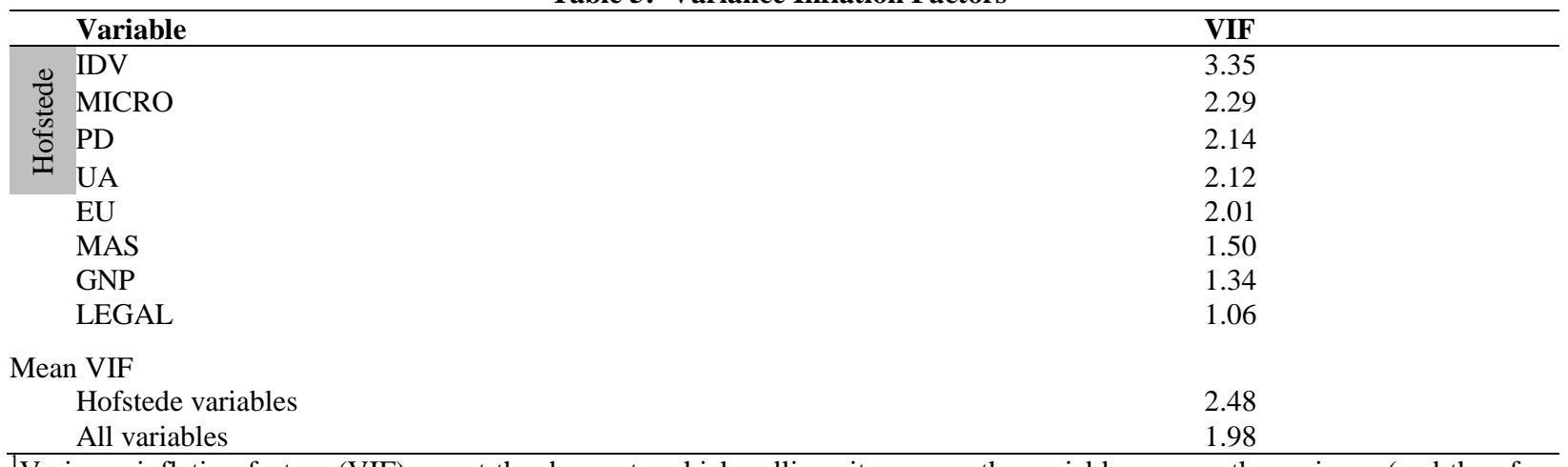

${ }^{\mathrm{T}}$ Variance inflation factors (VIF) report the degree to which collinearity among the variables causes the variance (and therefore the standard error) to be overstated. Overstated variances (standard errors) increase the likelihood of a type II error. Generally, single variable VIF values in excess of 10 are considered evidence of a severe collinearity problem. (Myers 1990) Additionally, Bowerman and O'Connel (1990) suggest that if the average VIF is greater than 1, then the collinearity problem will likely bias the standard errors sufficiently to induce inflated standard errors.

\footnotetext{
${ }^{5}$ The first formal adoption of IFRS occurred in 2002. Therefore, the DELAY variable for a country adopting in that year is zero.

${ }^{6}$ For countries that have not yet set an adoption year, we assign an adoption year of 2016. This equates to setting the DELAY variable equal to 14 (2016-2002). This assignment of adoption year permits us to compute a DELAY variable for these countries that is larger than for all countries that have set an adoption date. Further, the assignment of adoption year allows us to retain the countries without an adoption date and is the latest anticipated adoption date by US firms.
} 
Bowerman and O'Connel (1990) suggest that if the average VIF is greater than 1, then the collinearity problem will likely bias the standard errors sufficiently to induce inflated standard errors. The average VIF for all variables in our model is 1.98 and the average VIF for the Hofstede variables is 2.48. Our variables exhibit VIF levels well beyond the point where a collinearity problem is indicated. ${ }^{7}$ Severe collinearity problems can lead to inflated variances (almost by a factor of two in this case) and overstated standard errors, which will typically obscure the underlying relationships of interest. Much of the literature refers to this situation as an over-specified model, because the high collinearity indicates that the unique information represented by each of the variables in the model is small. The remedy is often to drop those variables responsible for inducing the collinearity in the model. In our case, however, it is the variables of interest that induce the collinearity. Therefore, we look to an alternative remedy for the collinearity problem: a ridge regression. ${ }^{8,9}$

A ridge regression addresses the inflated variance problem by using a best-fit method rather than the leastsquares approach employed by typical linear regression. ${ }^{10}$ Therefore, we re-estimate equation 3 as a ridge regression. In our implementation of the ridge regression we test for the sensitivity of our results to alternative variance inflation adjustment parameters (i.e., VIF corrections). Our model and findings are robust to alternative variance inflation parameters. ${ }^{11}$ The results are found in Table 6.

Table 6: Ridge Regression Results

\begin{tabular}{|c|c|c|c|c|}
\hline \multicolumn{5}{|c|}{$\overline{\text { DELAY }}=\mathrm{b}_{0}+\mathrm{b}_{1} \mathrm{IDV}+\mathrm{b}_{2} \mathrm{PD}+\mathrm{b}_{3} \mathrm{UA}+\mathrm{b}_{4} \mathrm{MAS}+\mathrm{b}_{5} \mathrm{MACRO}+\mathrm{b}_{6} \mathrm{LEGAL}+\mathrm{b}_{7} \mathrm{EU}+\mathrm{b}_{8} \mathrm{GNP}+\mathrm{e}$} \\
\hline & Coefficient & Standard Error & t-statistic & p-value \\
\hline IDV & 0.2643 & 0.0888 & 2.9800 & 0.0060 \\
\hline $\mathrm{PD}$ & $(0.2180)$ & 0.0996 & $(2.1900)$ & 0.0370 \\
\hline UA & 0.1991 & 0.1141 & 1.7400 & 0.0920 \\
\hline MAS & 0.2817 & 0.1375 & 2.0500 & 0.0500 \\
\hline MACRO & $(0.0436)$ & 0.1630 & $(0.2700)$ & 0.7910 \\
\hline LEGAL & $(0.4371)$ & 0.1788 & $(2.4500)$ & 0.0210 \\
\hline EU & 0.2327 & 0.2531 & 0.9200 & 0.3660 \\
\hline GNP & 0.2544 & 0.3287 & 0.7700 & 0.4450 \\
\hline Observations ${ }^{1}$ & 37 & & & \\
\hline F-test & 0.0059 & & & \\
\hline Adjusted $\mathrm{R}^{2}$ & 0.3616 & & & \\
\hline
\end{tabular}

${ }^{1}$ The regression model excludes Iran and Turkey because both countries lack data necessary for the MACRO variable.

Based on Table 3, we find that $D E L A Y$ is positively and significantly $(p<.01)$ associated with the Hofstede measure of individualism $(I D V)$. Since individualism values independent thought and a concern for one's own and one's immediate friends and family over the good to society as a whole, it would follow that if the individuals thought that superior (or at a minimum well-known to those in question) financial information was being generated,

\footnotetext{
${ }^{7}$ The variance inflation factor (VIF) measures the degree that the variances are overstated. Therefore, a VIF of 1.98 indicates that the average variance estimates are overstated by a factor of roughly 2.0.

${ }^{8}$ Ridge regression was formally introduced by Hoerl and Kennard (1970). The Ridge Regression procedure addresses the instability of OLS due to the near singularity of X'X. (Anemiya 1985).

${ }^{9}$ Yet another solution for collinearity is to apply a factor analysis and use the new variables (factors) in the analysis. We apply this method using an oblique rotation and a total of four factors are generated. We find that the newly created variables (factors) are all significantly associated with DELAY at conventional levels. The model is also significant. While this supports our overall hypothesis, we do not present it formally because interpretation of the factors in the context of our hypotheses is not possible.

${ }_{10}$ While this approach induces some bias in the parameter estimates, it is able to circumvent the larger problem of variance inflation associated with collinearity in linear regression. For a complete discussion of ridge regressions, see Hoerl and Kennard (1970) and Anemiya (1985)

${ }^{11}$ We report and discuss the results based on the parameters that optimally address the variance inflation in our data. The results are consistent with those reported here. We center the data and impose a variance of 1 for all variables. Therefore, the ridge results are interpreted in terms of changes in standardized Z-scores. Further we also replicate our analysis using a maximum likelihood estimation approach to ascertain if the normality assumptions are valid.
} 
the individuals involved might advocate either not joining IFRS or might exercise greater caution which would result in a longer adoption time for the financial regulators. Thus, a greater sense of independence, or a lower need for belonging, is associated with a longer delay in the adoption of IFRS.

The negative relationship between $D E L A Y$ and $P D$ is significant at the $p<.05$ level. $P D$ measures the degree to which differences in relative power or authority is accepted in the society. Smaller levels in the $P D$ measure reflect a greater degree of comfort with disparate power and authority. This variable is negatively related to $D E L A Y$ reflecting the tendency for those cultures with lower acceptance of power differentials to adopt later. This is indicative of those within the culture desiring a sense of control over their own destiny, in this case their financial reporting, and not wishing to cede control to an international/outside group to set the rules, and effectively the playing field, under which they would operate. A lack of comfort would be felt because the power to set the rules would lie outside of what would be perceived as the individual's realm of influence, causing those in charge of making the decision to move to IFRS to put off such a determination, which in turn causes the country to adopt these outside rules later than a country whose constituency had higher power distance scores.

Masculinity $(M A S)$ is significantly $(p<.050)$ and positively related to DELAY, so increasing levels of masculinity are associated with greater delays in the adoption of IFRS. Since masculinity suggests a lack of needing to belong to a group and more of a business drive, countries with higher masculinity scores would likely resist the adoption of IFRS from their national systems which had been developed specifically for their business needs. The final tested Hofstede cultural dimension, uncertainty avoidance $(U A)$, is significant at the $(p<.100)$ level in influencing the $D E L A Y$ variable. This indicates that increased levels of uncertainty avoidance are related to longer adoption times for IFRS. This is interesting because it implies that individuals in charge of the adoption process are likely being influenced by the desire to know the outcomes of the financial decisions, thus they wish to stick with the familiar home-country financial disclosure requirements. Thus although eventually adopting IFRS, it may take the constituency longer to get familiar and comfortable with the outcomes associated with using IFRS as the financial reporting method and thus longer adoption periods are required to make the transition. So, increasing degrees of discomfort with uncertainty is associated with larger delays in adoption.

Finally, DELAY is also significantly $(p<.050)$ negatively associated with the $L E G A L$ variable; a legal environment more closely tied to common law is associated with an increase in the DELAY variable. Contributions made by other variables in the model are not statistically significant in predicting a country's movement to IFRS. This research extends the work of Clements, Neill, and Stovall (2010) by suggesting the importance of certain elements of culture and the legal environment in predicting when a country will adopt IFRS.

\section{SUMMARY AND DISCUSSION}

The importance of cultural norms on social behavior and systems organizing them is well established in the literature. We extend the literature first by establishing that culture plays an important role in a country's decision to join the European Union, and second, by demonstrating that these cultural factors influence the rapidity with which countries have embraced IFRS as their primary financial reporting mechanism. Through an examination of 39 countries, we find support for the claim that the cultural characteristics and the legal variable are associated with the timing of conversion to a common international financial reporting system. To the extent that we view financial reporting as one of the languages of business, serving both to provide useful information and also an agency solution, it seems reasonable to expect that cultural norms would be central to the adoption of IFRS; cultural factors continue to maintain their influence even within our globalized economy.

We identify two important limitations to our analysis. First, countries without reported Hofstede measures were excluded from our analysis. Also, because two countries (Iran and Turkey) have data for all variables except MACRO, they are included in our entire analysis with the exception of the ridge regression in Table 6 . Therefore, our analysis incorporates 39 countries with the exception for the ridge regression, which is based on 37 countries. Second, the international conversion to IFRS is far from complete. We analyze the historical adoption and intended adoption and make an assumption about those countries not yet claiming a conversion date; the dependent variable in our analysis (DELAY) is then estimated for those countries not having adopted. Our study will need to be revisited if countries initiate an adoption timeline different from that currently reported. 


\section{ACKNOWLEDGEMENTS}

The authors would like to thank Drs. A. A. Neidermeyer and Davide P. Cervone for their comments on this paper.

\section{AUTHOR INFORMATION}

Presha E. Neidermeyer, Ph.D. CPA is a faculty member in the Division of Accounting within West Virginia University's College of Business and Economics. Her research specialty includes the impact of culture on behavior and gender issues, and includes articles published in numerous journals. She is the co-author of Use What You Have: Resolving the HIV/AIDS Pandemic. Her teaching specialties include financial and international accounting. She is an active participant in various organizations benefiting charities in Africa, and she has led multiple teams to Africa of business people interested in using their special skills to help minimize the impact of the AIDS Pandemic. E-mail: pneidermeyer@gmail.com (Corresponding author)

Jack Dorminey, Ph.D. is a faculty member in the Division of Accounting within West Virginia University's College of Business and Economics. His research centers around financial reporting decisions and the effect on the beliefs of market participants. Prior to his academic appointment was employed by the Federal Reserve Bank of Richmond in Richmond, Virginia. E-mail: jack.dorminey@mail.wvu.edu

Alan J. Wilson holds a Bachelor's of Science in Business Administration with a Major in Accounting from West Virginia University and is currently pursuing a law degree from WVU. Alan interned at a multi-state bank holding company prior to working as an intern at KPMG where he worked in both the financial services audit practice and the state and local tax practice. Alan's research interests include areas pertaining to banking, micro-lending, and personal financial planning. E-mail: ajw6546@yahoo.com

\section{REFERENCES}

1. Amemiya, T (1985), Advanced Econometrics. Boston, MA: Harvard University Press

2. Doupnik, T. and Salter, S. (1993). An Empirical Test of a Judgmental International Classification of Financial Reporting Practices. Journal of International Business Studies. First Quarter, 41-60.

3. Gernon, H. and Meek, G. (2001). Accounting: An International Perspective. (5 $5^{\text {th }}$ edition). Irwin McGrawHill, 2001.

4. Gray, S. (1988). Towards a Theory of Cultural Influence on the Development of Accounting Systems Internationally. Abacus 24, 1-15.

5. Hoerl, A.E., Kennard, R.W. (1970). Ridge Regression: Applications to Nonorthogonal Problems. Technometrics. 12, 69-82.

6. Hofstede, G. Analysis. (1998). Retrieved April 11, 2009, from http://www.cyborlink.com/besite/hofstede.htm

7. Hofstede, G. 1980. Culture's Consequences. London, UK: Sage Publications.

8. International Accounting Standards Committee. http://www.iasb.org/Use+around+the+world/Use+around+the+world.htm

9. Nobes, C. (1983). A Judgmental International Classification of Financial Reporting Practices. Journal of Business Finance and Accounting. 10(1), 1-19.

10. Nobes, C. (1998). Towards a General Model of the Reasons for International Differences in Financial Reporting. Abacus 34(2), 162-187. 